\title{
The Number of Podocyte Slit Diaphragms Is Decreased in Minimal Change Nephrotic Syndrome
}

\author{
JAAKKO PATRAKKA, ANNE-TIINA LAHDENKARI, OLLI KOSKIMIES, CHRISTER HOLMBERG, \\ JORMA WARTIOVAARA, AND HANNU JALANKO \\ Hospital for Children and Adolescents and Biomedicum Helsinki, University of Helsinki, 00290 Helsinki, \\ Finland [J.P., A-T.L., O.K., C.H., H.J.]; Electron Microscopy Unit, Institute of Biotechnology, University \\ of Helsinki, 00560 Helsinki, Finland [J.P., A-T.L., J.W.]
}

\begin{abstract}
The pathophysiology of proteinuria in acquired kidney diseases is mostly unknown. Recent findings in genetic renal diseases suggest that glomerular epithelial cells (podocytes) and the slit diaphragm connecting the podocyte foot processes play an important role in the development of proteinuria. In this work we systematically evaluated the podocyte slit pores by transmission electron microscopy in two important nephrotic diseases, minimal change nephrotic syndrome (MCNS) and membranous nephropathy (MN). As controls, we used kidneys with tubulointerstitial nephritis (TIN). Effacement of podocyte foot processes was evident in proteinuric kidneys. However, quite normal looking foot processes and slit pores with varying width were also observed. Careful analysis of slit pores revealed, that the proportion of the pores spanned by the linear image of slit diaphragm, was reduced by $39 \%$ in kidneys from MCNS patients (1265 pores analyzed) compared with TIN samples (902 pores
\end{abstract}

\section{ABSTRACT}

analyzed, $p=0.0003$ ). To enhance the detection rate of the slit diaphragms, the "empty" podocyte pores were further analyzed with tilting series from -45 to +45 . This revealed the linear diaphragm image in $71 \%$ and $26 \%$ of the slits in TIN and MCNS kidneys, respectively $(p=0.0003)$. In contrast to findings in MCNS, no significant reduction of the slit diaphragms were seen in MN kidneys compared with the controls. The results suggest that MCNS is associated with disruption of glomerular slit diaphragms. (Pediatr Res 52: 349-355, 2002)

Abbreviations
MCNS, minimal change nephrotic syndrome
MN, membranous nephropathy
TIN, tubulointerstitial nephritis
GBM, glomerular basement membrane
NPHS1, congenital nephrotic syndrome of the Finnish type

The primary urine in the kidney forms by ultrafiltration of plasma components through the glomerular capillary wall into the urinary space (1). This glomerular filtration barrier is composed of a fenestrated endothelium, glomerular basement membrane (GBM) and epithelial cell (podocyte) layer. The podocyte layer consist intercalated foot processes, which are connected by 35-45 nm wide extracellular structure, termed the slit diaphragm. Normally, water and small plasma solutes filtrate easily through this sieve but the passage of proteins with the size of albumin and larger is almost completely restricted. The GBM has been thought to be the most important component in this size and charge selective sieving, and defects in the GBM have been regarded responsible for proteinuria in many

December 31, 2001; April 3, 2002.

Correspondence: Hannu Jalanko M.D., Hospital for Children and Adolescents, University of Helsinki, 00290 Helsinki, Finland; e-mail:hannu.jalanko@hus.fi

This study was supported by The Sigrid Juselius Foundation, The Ulla Hjelt Fund of The Foundation for Pediatric research, The Finnish Academy, The Paulo Foundation, and The Helsinki University Central Hospital Research Fund.

DOI: 10.1203/01.PDR.0000025285.72240.11 glomerular diseases (2). Recent findings, however, have challenged the central role of the GBM in nephrotic diseases $(3,4)$.

Proteinuria is constantly associated with an effacement of podocyte foot processes, which has generally been regarded as a secondary phenomenon (5). Recent discoveries in the genetic diseases, however, suggest that podocytes may play a primary role in the development of proteinuria $(6,7)$. Mutations in NPHS1 gene coding for a podocyte specific protein, nephrin, are responsible for the congenital nephrotic syndrome of the Finnish type (NPHS1) $(8,9)$. Similarly, mutations in NPHS2 gene coding for another podocyte protein, podocin, are associated with a hereditary form of focal segmental glomerulosclerosis (FSGS) (10). Nephrin and podocin both localize at the slit diaphragm area (11-13) suggesting that the slit diaphragm has a crucial role in restricting the passage of plasma proteins into urine.

Recently we found that severe mutations (Fin-major and Fin-minor) in the NPHS1 lead to a total absence of nephrin in kidney glomerus of the Finnish NPHS1 patients (14). More interestingly, the slit diaphragms were completely missing in 
these kidneys as studied by electron microscopy suggesting that the "empty" filtration slits probably served as the route for protein leakage in this disease. These findings prompted us to perform a systematic electron microscopic evaluation of the podocyte filtration slits in two important nephrotic diseases, minimal change nephrotic syndrome (MCNS) and membranous nephropathy (MN). Our results suggest that disruption of the slit diaphragm is involved in the pathophysiology of proteinuria in MCNS.

\section{METHODS}

Renal samples. Renal tissue blocks for morphologic electron microscopy were obtained by percutaneous needle biopsy. Biopsies were taken on clinical indications from patients treated during the years 1969-2000 at the Hospital for Children and Adolescents, or at the Department of Internal Medicine, University of Helsinki, Finland. The diagnoses were based on typical clinical features, laboratory investigations, and kidney pathology. The pathologic evaluation included light and electron microscopy as well as routine immunofluorescence staining for immunoglobulins and complement components.

Renal tissue samples came from eleven patients with MCNS, from five patients with MN, and from eight control patients with tubulointerstitial nephritis (TIN) (Table 1). Age at the time of biopsy ranged between 1 and 55 y (median 13). While patients with MCNS were typically small children or young adults, patients with TIN and MN were generally older. The level of proteinuria at the time of biopsy was divided into moderate $(0.3-2.0 \mathrm{~g} / \mathrm{L})$, marked $(2.0-4.0 \mathrm{~g} / \mathrm{L})$, and heavy $(>4.0 \mathrm{~g} / \mathrm{L})$. Protein concentration $(\mathrm{g} / \mathrm{L})$ in the urine specimens taken at the time of renal biopsy was used for this grading, since data on the total daily protein excretion was not available in most patients. Marked to heavy proteinuria was found in eight patients with MCNS, while three patients were in remission shortly after steroid-treatment (Table 1). All five patients with $\mathrm{MN}$ were proteinuric at the time of biopsy. Three patients with TIN had slight (tubular) proteinuria. This study was

Table 1. Diagnosis, patient age, level of proteinuria, electron microscopic (EM) findings, and therapy in patients included in this study

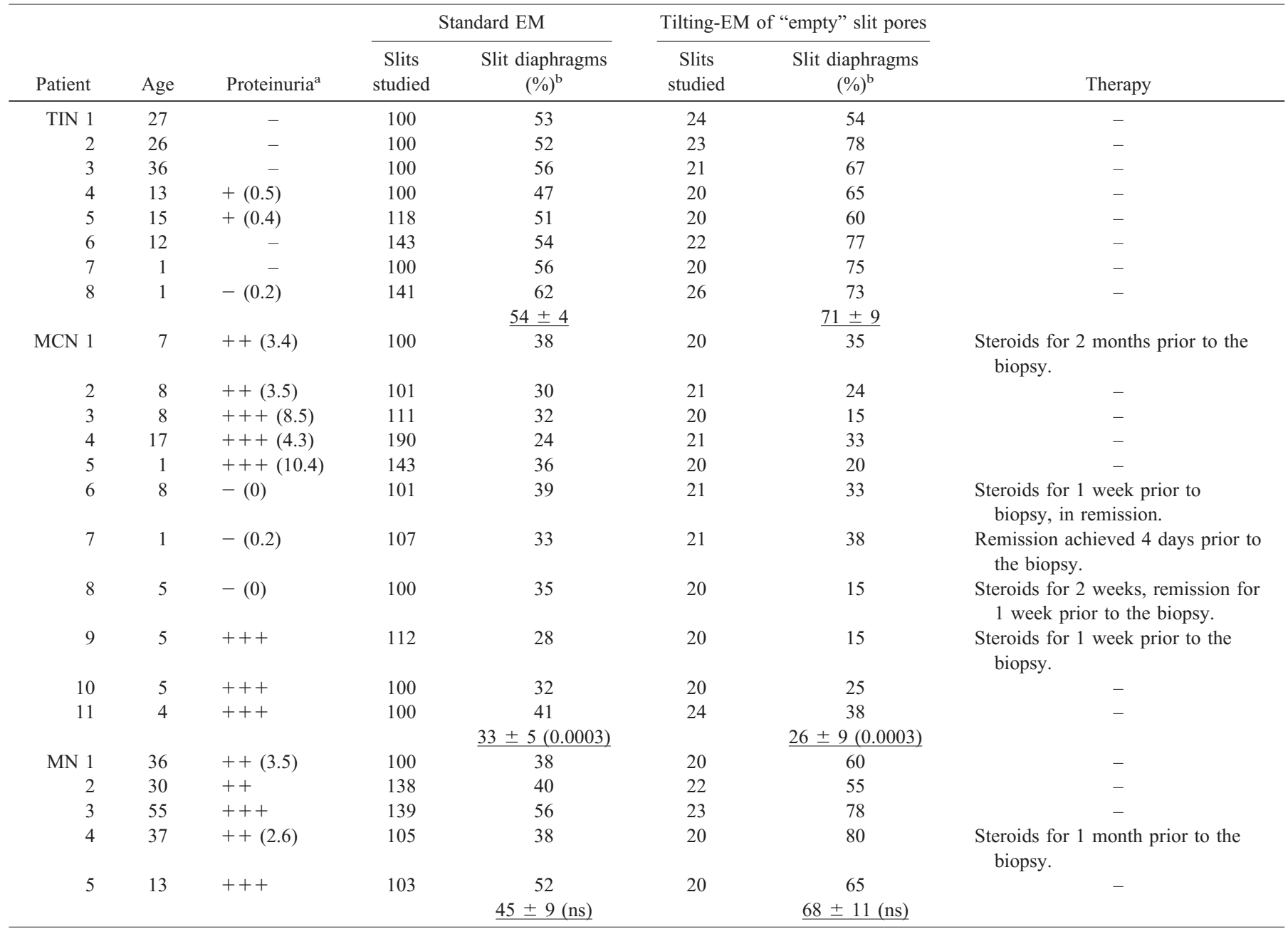

${ }^{a}$ Proteinuria was divided into four categories: $-=<0.3 \mathrm{~g} / \mathrm{L},+=0.3-2 \mathrm{~g} / \mathrm{L},++=2-4 \mathrm{~g} / \mathrm{L}$, and $+++=>4 \mathrm{~g} / \mathrm{L}$. Amount of proteinuria showed as $\mathrm{g} / \mathrm{L}$ in cases where data available.

${ }^{\mathrm{b}}$ The proportion of the podocyte pores where the image of the slit diaphragm filament is detectable.

Patients with MCNS and MN are compared against patients with TIN (Mann-Whitney U test).

Results for patient groups are given as mean $\pm \mathrm{SD}$ ( $p$ value, $\mathrm{ns}=$ not significant). 

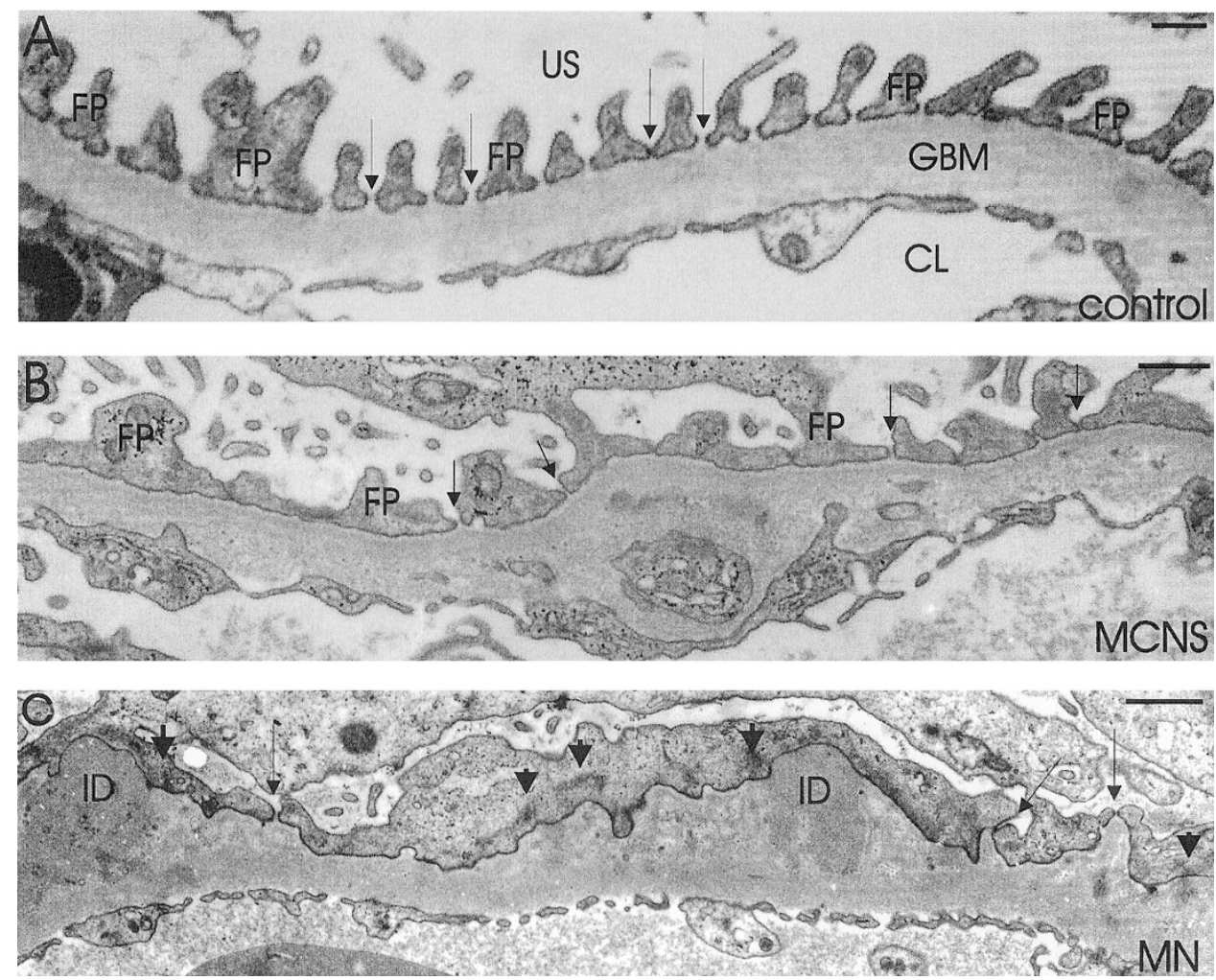

Figure 1. Electron microscopic views of the glomerular capillary wall. (A) In TIN, the morphology of the capillary wall is normal. The regular sized podocyte foot processes (FP) are connected by an intact slit diaphragm (arrows). CL = capillary lumen, US = urinary space. (B) In MCNS, the broad epithelial sheets cover the GBM, and the frequency of the podocyte pores (arrows) is decreased. (C) The effacement of the podocyte foot processes is evident in the capillary wall of a patient with MN, leading to a decrease in the frequency of slit pores. Subepithelial immune deposits (ID) are present in the GBM. Occasionally, filaments of the podocyte cytoskeleton are concentrated near the immune deposits (arrowheads). Bar $=100 \mathrm{~nm}$.

approved by the ethical committee of the Hospital for Children and Adolescents, University of Helsinki, Finland. This committee gave the permission to use the historical biopsy material and clinical data for this study.

Electron microscopy. The preparation of the renal biopsies for electron microscopy was performed according to normal procedures. The tissue blocks were cut into $1-\mathrm{mm}^{3}$ pieces, immersed into $2.5 \%$ glutaraldehyde fixative (phosphate buffered, $\mathrm{pH}$ 7.2) for $1-3 \mathrm{~h}$, followed by Epon embedding. After thin sectioning, the samples were poststained with uranyl acetate and lead citrate. The samples were evaluated with a Jeol 1200 EX electron microscope (Tokyo, Japan) at $60 \mathrm{kV}$.

One glomerulus was analyzed from each sample. The proportion of the podocyte slits, where the linear image of the slit diaphragm was detectable, was counted. The counting was started from a randomly determined part of the glomerular capillary wall. The pores, where the sectioning angle made the evaluation of the slit diaphragm impossible, were ignored, and a minimum of 100 slits was analyzed in each sample. To test the reliability of the slit diaphragm analysis, the investigation was performed twice. The variances between the two analyses were 7,11 , and $16 \%$ in samples from patients with TIN, MCNS, and MN, respectively.

Because the visibility of the linear image of slit diaphragm was dependent on the angle of the cross-section, the samples were further analyzed by tilting the thin section under the electron microscope. A tilt series from $-45^{\circ}$ to $+45^{\circ}$ along the $x$ axis of the section was performed on the pores, where the linear image of the slit diaphragm was first undetectable. A minimum of 20 slit pores with missing linear slit diaphragms were analyzed with this tilting series. This tilting analysis was performed independently from the first evaluation. The electron microscopic findings were analyzed with Mann-Whitney $\mathrm{U}$ test.

\section{RESULTS}

TIN. The ultrastructure of the glomerular capillary wall was normal in renal samples with TIN (used as controls) (Fig. 1A). Regular sized podocyte foot processes were present, and the podocyte filtration pores appeared normal (Fig. 2A). The width of the filtration slits varied approximately from 35 to $45 \mathrm{~nm}$. Since the angle of slit cross-section varied, the linear image of the slit diaphragm was not detectable in every pore. In fact, it was observed in only $54 \%(487 / 902$, median $54 \%)$ of the filtration slits studied in eight samples with TIN (Table 1). After the first counting, a separate tilting analysis was performed on podocyte pores where the slit diaphragm was missing. Of the 176 pores analyzed, the tilting revealed a linear slit diaphragm in 125 (median 69\%) of the podocyte pores (Fig. $3 A, B)$.

MCNS. In kidneys with MNCS, the most prominent finding in the glomerular capillary wall was the effacement of the podocyte foot processes (Fig. 1B). The foot processes had an 
irregular size but they showed no detachment from the GBM. Variation in the width of the remaining podocyte pores was present. Exceptionally wide slits, up to $70 \mathrm{~nm}$, were occasionally observed (Fig. $2 B$ ). On the other hand, the cell membranes of the foot processes were often in close contact (Fig. 2C). The percentage of the slit pores, where the slit diaphragm was detected, varied from $24 \%$ to $41 \%$ (median $34 \%, 1265$ slits evaluated) in the eleven MCNS samples (Fig. 4A). The proportion of pores with the slit diaphragm was reduced by $39 \%$ in MCNS kidneys compared with the TIN kidneys ( $p=$ 0.0003 , Mann-Whitney U test). Instead, some fuzzy material was occasionally detectable in these slits missing the linear image of the slit diaphragm (Fig. 3C). The tilting analysis of the "empty" slit pores revealed the slit diaphragms in $26 \%$ $(59 / 228$, median $25 \%$ ) of the slits analyzed (Fig. 3C, $D \& 4 B$ ). This was also significantly less than in TIN kidneys $(p=$ 0.0003 , Mann-Whitney $U$ test). In addition, junctions with ladder-like structures were observed in 4/11 MCNS glomeruli (data not shown). These structures were detected in the intercellular space of podocytes close to the GBM, as has been described in immature glomeruli (14).

$M N$. In the five samples of MN, the similar effacement of podocyte foot processes was seen as in MCNS (Fig. 1C). Moreover, electron-dense deposits were present on the subepithelial surface of the GBM. Also, filaments within the podocyte cytoplasm near these immune deposits showed condensation (Fig. $1 C$ and $2 D$ ). The number of MN podocyte pores with detectable linear images of slit diaphragms varied between 38 and $56 \%$ (median 38\%, 585 slits evaluated) in the standard (untilted) electron microscopic analysis (Table 1, Fig. 4A). This was less than in TIN kidneys but the difference was not statistically significant ( $p=0.09$, Mann-Whitney U test). After tilting the linear image of the slit diaphragm became visible in $68 \%(71 / 105$, median $65 \%)$ of the podocyte pores where it originally was undetectable which was comparable to that in TIN kidneys (71\%). In addition, junctions with ladder-like structures were found in 3/5 of the MN glomeruli (Fig. 2D).

\section{DISCUSSION}

Understanding of the glomerular filtration process and the pathogenesis of proteinuria is essential for nephrology. In the present study, we performed a systematic evaluation of the ultrastructure of the glomerular filtration slit in two common nephrotic disorders, MCNS and MN. The major finding was that MCNS kidneys showed not only effacement of podocyte foot processes but also a significant reduction of the linear image of slit diaphragm in the remaining podocyte pores. This suggests that slit diaphragms might be a target of the pathogenetic process in this common pediatric kidney disease.

Mechanisms leading to proteinuria in MCNS as well as in other nephrotic diseases are not well known. Defects in the GBM and especially reduction of its anionic charge have been suggested to explain the leakage of negatively charged plasma proteins into urine in some disorders (2). On the other hand, detachment of the podocyte foot processes from the GBM has correlated with the onset of proteinuria in animal models (15). Areas of denuded GBM could then serve as the sites for the
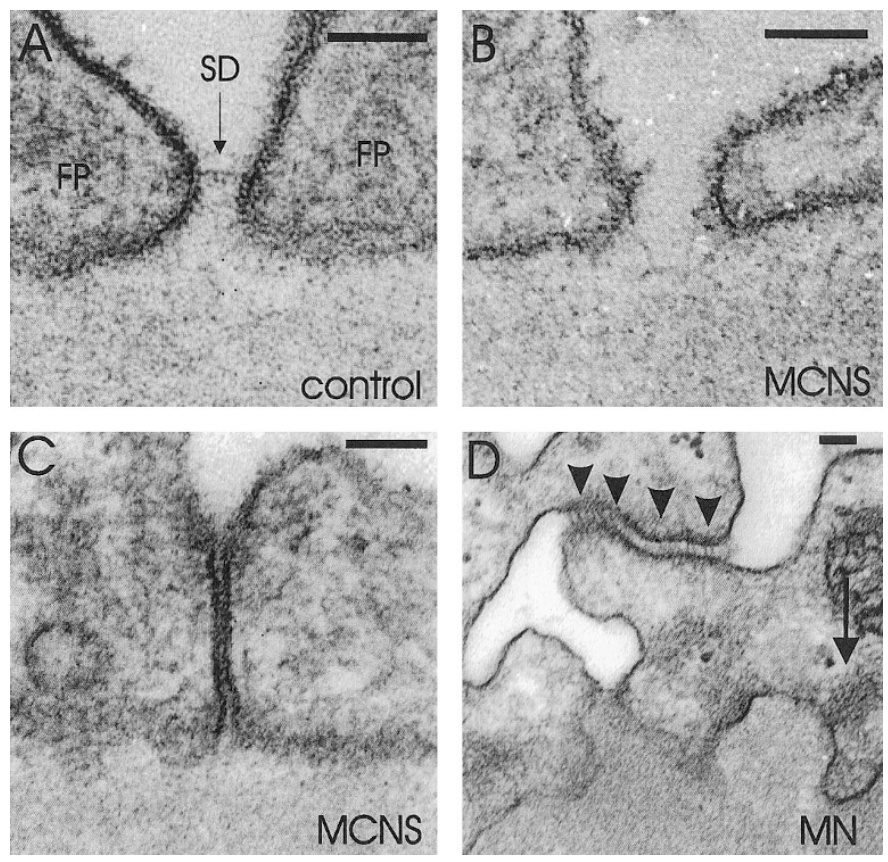

Figure 2. High-power views of the podocyte filtration pores. $(A)$ In TIN, the podocyte foot processes (FP) are connected by a thin linear image of the slit diaphragm (SD). (B) In proteinuric kidneys (MCNS), widened podocyte slits are found, and the visible SDs are missing in most filtration pores. (C) Also, the adjacent podocyte foot processes membranes are often in close contact. $(D)$ Podocyte junctions with ladder-like structures (arrowheads) are found in about half of the nephrotic glomeruli. These ladders are observed as a series of dense ridges spanning the intercellular space of podocytes. Note the filament concentrates in the podocyte cytoplasm next to the immune deposit in the GBM (arrow). Bar $=50 \mathrm{~nm}$.

protein leakage (5). Despite of extensive studies, neither of these mechanisms, however, has been proven to play a key role in primary nephrotic diseases in man. In electron microscopy, proteinuric kidneys show effacement of podocyte foot processes with disappearance of many of the podocyte pores (5). This process has generally been regarded as a secondary phenomenon - the consequence rather than the cause of protein leakage - and little attention has been paid to the remaining podocyte pores and slit diaphragms. To our knowledge, no systematic evaluation of the slit diaphragms in acquired kidney diseases has been performed. The recent findings in genetic disorders and some animal models, however, indicate that the podocyte pores may be critical in the pathogenesis of proteinuria $(4,7)$.

The technical problem in the electron microscopic analysis of the slit diaphragms is that the linear image of the diaphragm is seen only when the angle of the thin section is favorable. Even in kidneys with no glomerular lesions (TIN), the linear slit diaphragm was observed in only half of the filtration pores. Changing the viewing angle (tilting around the $x$ axis) however, caused the slit diaphragm to become visible in over $70 \%$ of the normal podocyte pores, where it was originally undetectable, so that the overall proportion of slits with the detectable linear image of the slit diaphragm raised to $87 \%$. In MCNS glomeruli, the lack of detectable linear slit diaphragms in pores was evident both in direct viewing and after tilting, so that the total proportion of the slits with detectable image of the 

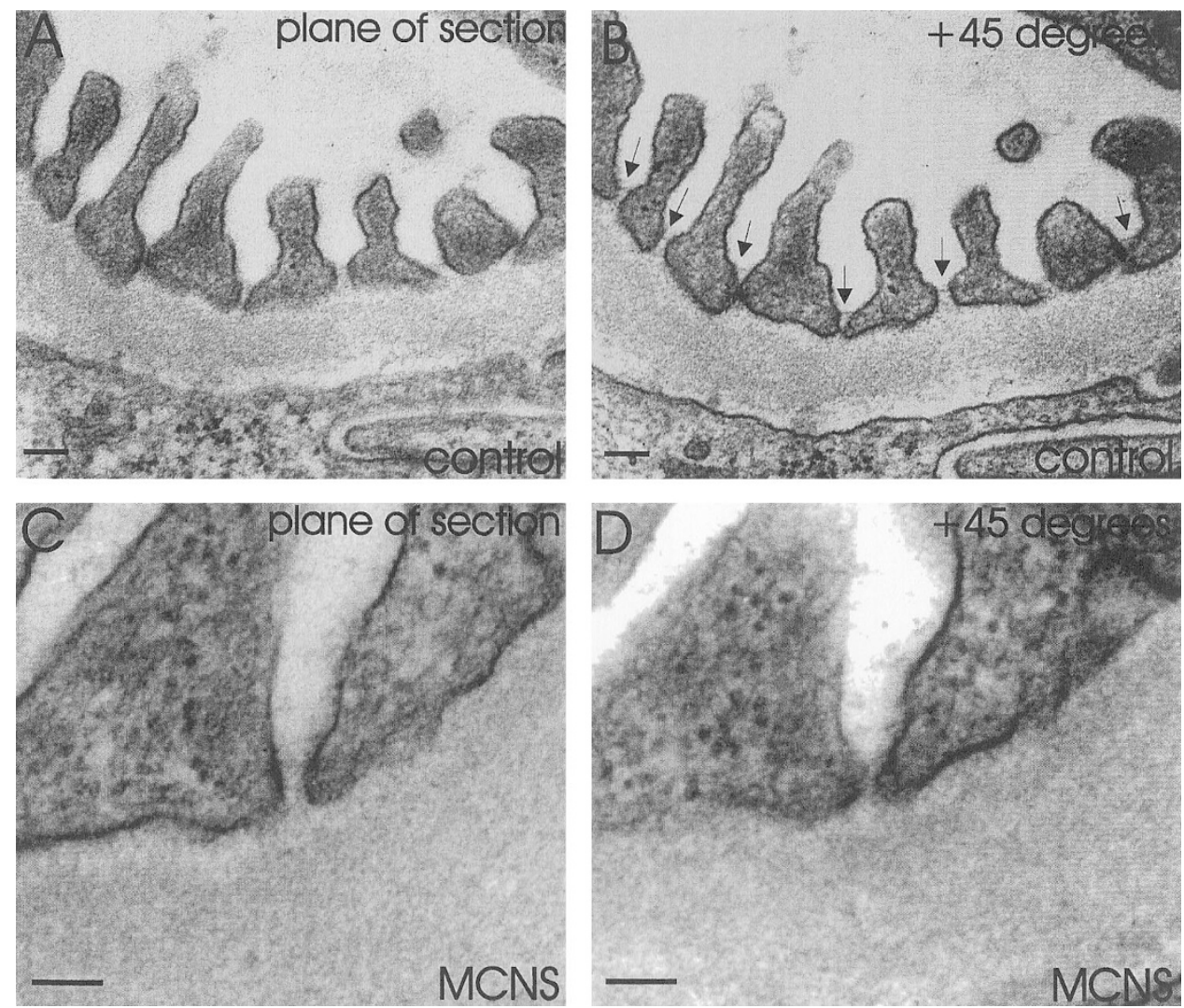

Figure 3. The electron microscopic views of the podocyte slit pores where the thin sections have been tilted under the microscope. $(A, B)$ In TIN kidney, the linear podocyte slit diaphragm is first $\left(0^{\circ}\right)$ not detectable in any of the seven pores analyzed. After tilting $\left(+45^{\circ}\right)$, the linear image of slit diaphragm becomes evident in six of the seven pores analyzed. $(C, D)$ In a MCNS glomerulus sample, the linear slit diaphragm remains undetectable even after the tilting analysis. Only some fuzzy material is seen in the slit pore. Bar $=100 \mathrm{~nm}$.

slit diaphragm was $50 \%$. Hence, we feel that the finding really reflects an alteration of the slit diaphragms in this disorder. The fact, that these glomeruli also contained junctions with ladderlike structures, supports this finding. Junctions with ladders are believed to represent a primitive form of the slit diaphragm and they are found both during normal glomerulogenesis and in proteinuric disorders such as puromycin nephrosis in rats (16-18).

What is the significance of this finding? The fact that slit pores in MN patients with significant proteinuria looked normal favors the idea that the disappearance of slit diaphragm image in MCNS kidneys is not secondary to proteinuria itself. Importantly, the electron microscopic findings in MCNS were similar to those in kidneys with congenital nephrotic syndrome (NPHS1), which is characterized by massive proteinuria from the birth. In NPHS1 children with severe mutations (Fin-major and Fin-minor), the major slit diaphragm component, nephrin, is missing, and all podocyte pores are "empty" (14). These slits might serve as the site for protein leakage in both conditions, which is not surprising since the filtration of water and small plasma solutes normally occur through these pores. Proteins might use the same route, if the slit diaphragms are disrupted. It is also remarkable that in MCNS and NPHS1 the podocyte foot processes seem to be firmly attached to the GBM without areas of detachment (14).

Although it is tempting to speculate that slit diaphragm would serve as a "gate" to plasma proteins, the association of the electron microscopic findings and protein leakage seems not to be so strict. Proteinuria may occur with apparently normal looking slit diaphragm, as is the case in some NPHS1 patients with minor mutations (14). Also, when anti-nephrin antibodies are injected into rats, proteinuria appears in a few hours but the electron microscopic findings remain quite normal $(19,20)$. Moreover, three of the eight MCNS patients in our study had reached remission 4-7 d before the renal biopsies and still showed slit pores without the linear image of slit diaphragm. The slit diaphragm is a network of proteins and the electron microscopic line obviously reflects this thin network seen in side view and even then only very roughly. For example, contrast staining of the slit diaphragm can vary markedly. Also, whether an "empty" slit pore indicates general disruption or loosening or a specific molecular change in this network, is not known. At the moment, the electron microscopic findings cannot be correlated to the functional state of the glomeruli. However, we feel that the similarity of the findings in MCNS and NPHS1 strongly suggests that the decisive pathogenetic changes in MCNS occur in the slit diaphragm area - not in the glomerular basement membrane.

Nephrin is believed to be a major component of the slit diaphragm and its expression in MCNS has recently been reported. Both normal and altered expression has been reported using immunohistochemistry and in situ hybridization $(21,22)$. The light microscopic findings, however, are not sensitive enough to detect ultrastructural changes. Immunoelectron mi- 

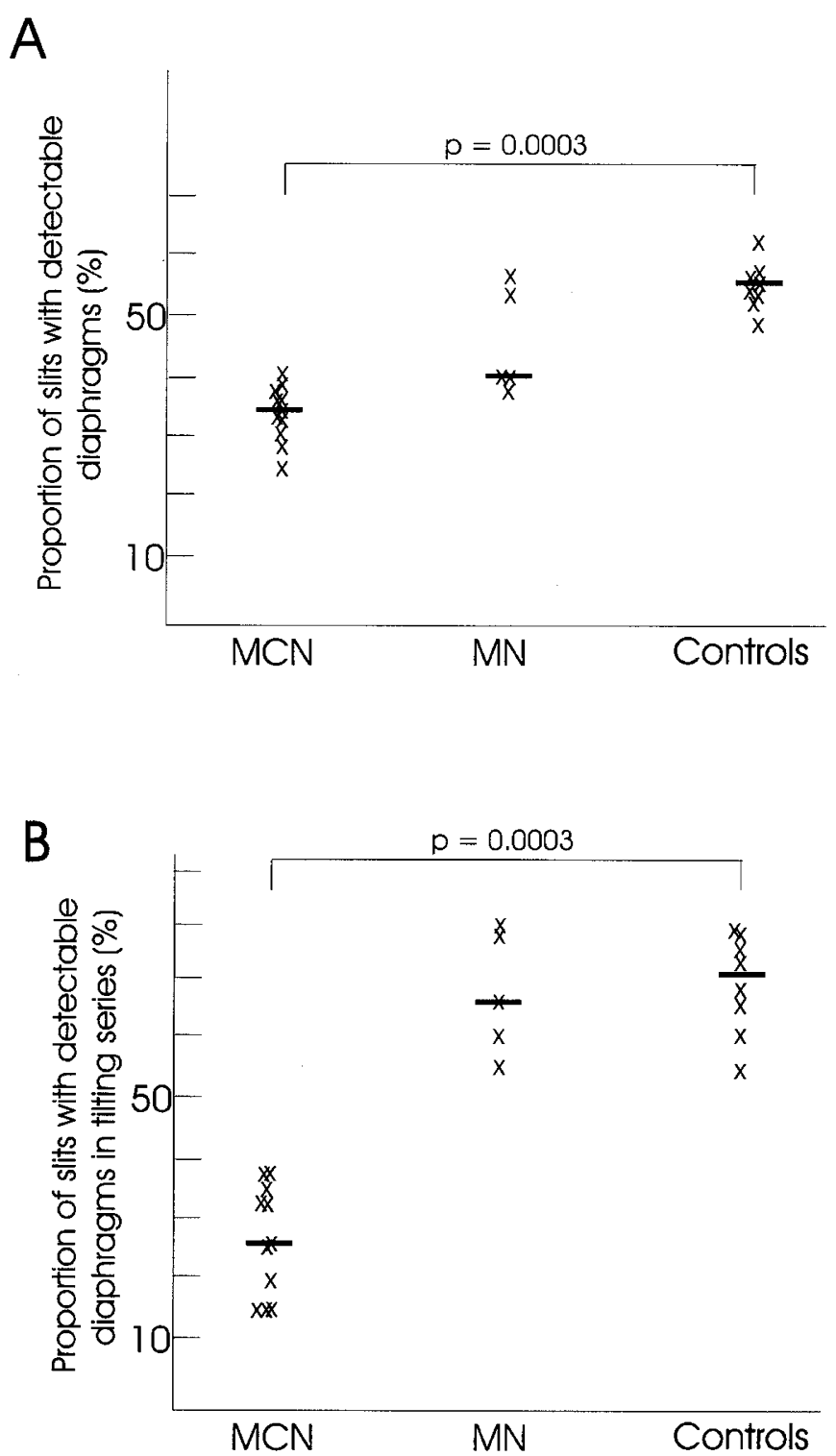

Figure 4. The proportion of the podocyte slit pores where the slit diaphragms are present in control (TIN) and nephrotic kidney samples. $(A)$ In standard transmission electron microscopy without specimen tilting, the number of detectable linear slit diaphragms is significantly reduced $(p=0.0003)$ in patients with MCNS compared with control group. There is no significant difference in this number between patients with $\mathrm{MN}$ and controls. $(B)$ In the tilting series from -45 to +45 degrees around the $x$ axis the proportion of the slits where linear diaphragms become evident is also significantly ( $p=0.0003)$ decreased in kidneys from patients with MCNS compared with controls, while the slit diaphragm number in MN kidneys resembles that of controls. Median values in each group are indicated as cross-bars.

croscopic studies give a better resolution, but in our experience the staining intensity even with strong anti-nephrin antibodies is so low that the interpretation is difficult (Patrakka et al. manuscript in preparation). Besides nephrin, proteins, such as FAT, P-cadherin and podocin, have been localized to the podocyte pore $(12,23,24)$ and more data on their expression and organization are needed.

Since the pathophysiology of MCNS is unknown, discussion on the possible mechanism leading to decrease in the number of the slit diaphragms is highly speculative. MCNS is sensitive to steroids and other immunosuppressive medication suggesting that the primary event is immunologic (25). It seems possible that soluble immunologic mediators could affect the slit diaphragms directly or indirectly through podocytes. The slit diaphragm components, intracellular linker proteins (ZO-1, CD2AP, alpha-actinin-4) and the actin cytoskeleton in the podocyte foot processes are believed to be in a continuous interplay, and toxic mediators interfering with this interplay might lead to disruption of the slit diaphragm and proteinuria $(11,13,23,24,26-28)$. This is supported by the fact that genetic defects in many of these components (nephrin, CD2AP, podocin, alpha-actin-4) cause fulminant proteinuria $(8,10,27-29)$.

\section{CONCLUSION}

In conclusion, the present results suggest that proteinuria in MCNS is caused by defective glomerular slit diaphragm rather than disorders in the GBM structure or its interaction with the podocyte foot processes. Further studies on the molecular architecture of the slit diaphragm and possible mediators interfering with this important filtration barrier are needed.

Acknowledgments. The authors thank the staff of electron microscopy unit for skillful technical assistance and Dr. Erik Qvist for help with the statistical analysis.

\section{REFERENCES}

1. Kanwar YS, Liu Z, Kashihara N, Wallner EI 1991 Current status of the structural and functional basis of glomerular filtration and proteinuria. Semin Nephrol 11:390-413

2. Raats CJ, van den Born J, Berden JH 2000 Glomerular heparan sulfate alterations: mechanisms and relevance to proteinuria. Kidney Int 57:385-400

3. Wickelgren I 1999 First components found for key kidney filter. Science 286:225226

4. Jalanko H, Patrakka J, Tryggvason K, Holmberg C 2001 Genetic kidney diseases disclose the pathogenesis of proteinuria. Ann Med 33:526-533

5. Smoyer WE, Mundel P 1998 Regulation of podocyte structure during the development of nephrotic syndrome. J Mol Med 76:172-183

6. Somlo S, Mundel P 2000 Getting a foothold in nephrotic syndromes. Nat Genet 24:333-335

7. Tryggvason K 1999 Unraveling the mechanisms of glomerular ultrafiltration: Nephrin, a key component of the slit diaphragm. J Am Soc Nephrol 10:2440-2445

8. Kestilä M, Lenkkeri U, Männikkö M, Lamerdin J, McCready P, Putaala H, Ruotsalainen V, Morita T, Nissinen M, Herva R, Kashtan CE, Peltonen L, Holmberg C, Olsen A, Tryggvason K 1998 Positionally cloned gene for a novel glomerular protein-nephrin-is mutated in congenital nephrotic syndrome. Mol Cell 1:575-582

9. Lenkkeri U, Männikkö M, McCready $P$, Lamerdin J, Gribouval $O$, Niaudet $P$, Antignac C, Kashtan CE, Holmberg C, Olsen A, Kestilä M, Tryggvason K 1999 Structure of the gene for congenital nephrotic syndrome of the Finnish type (NPHS1) and characterization of mutations. Am J Hum Genet 64:51-61

10. Boute N, Gribouval O, Roselli S, Benessy F, Lee H, Fuchshuber A, Dahan K, Gubler MC, Niaudet P, Antignac C 2000 NPHS2, encoding the glomerular protein, podocin, is mutated in autosomal recessive steroid-resistant nephrotic syndrome Nat Genet 24:349-354

11. Huber T, Kottgen M, Schilling B, Waltz G, Benzing T 2001 Interaction with podocin facilitates nephrin signaling J Biol Chem 276(45):41543-41546

12. Roselli S, Gribouval O, Boute N, Sich M, Benessy F, Attie T, Gubler MC, Antignac C 2002 Podocin localizes in the kidney to the slit diaphragm area Am J Pathol 160(1):131-139

13. Ruotsalainen V, Ljungberg P, Wartiovaara J, Lenkkeri U, Kestilä M, Jalanko H, Holmberg C, Tryggvason K 1999 Nephrin is specifically located at the slit diaphragm of glomerular podocytes. Proc Natl Acad Sci U S A 96:7962-7967

14. Patrakka J, Kestilä M, Wartiovaara J, Ruotsalainen V, Tissari P, Lenkkeri U, Männikkö M, Visapää I, Holmberg C, Rapola J, Tryggvason K, Jalanko H 2000 Congenital nephrotic syndrome of the Finnish type (NPHS1): Features resulting from different mutations in different patients. Kidney Int 58:972-980

15. Whiteside C, Prutis K, Cameron R, Thompson J 1989 Glomerular epithelial detachment, not reduced charge density, correlates with proteinuria in adriamycin and puromycin nephrosis. Lab Invest 61:650-660

16. Ruotsalainen V, Patrakka J, Tissari P, Reponen P, Hess M, Kestilä M, Holmberg C, Salonen R, Heikinheimo M, Wartiovaara J, Tryggvason K, Jalanko H 2000 Role of nephrin in cell junction formation in human nephrogenesis. Am J Pathol 157:1905-1916 
17. Ryan GB, Rodewald R, Karnowsky MJ 1975 An ultrastructural study of the glomerular slit diaphragm in aminonucleoside nephrosis. Lab Invest 33:461

18. Schneeberger EE, Grupe WE 1976 The ultrastructure of the glomerular slit diaphragm in autologous immune complex nephritis. Lab Invest 34:298

19. Orikasa M, Matsui K, Oite T, Shimizu F 1988 Massive proteinuria induced in rats by a single intravenous injection of a monoclonal antibody. J Immunol 141:807814

20. Topham PS, Kawachi H, Haydar SA, Chugh S, Addona TA, Charron KB, Holzman LB, Shia M, Shimizu F, Salant DJ 1999 Nephritogenic mAb 5-1-6 Is directed at the extracellular domain of rat nephrin. J Clin Invest 104:1559-66

21. Patrakka J, Ruotsalainen V, Ketola I, Holmberg C, Heikinheimo M, Tryggvason K, Jalanko H 2001 Expression of nephrin in pediatric kidney diseases. J Am Soc Nephrol 12:289-296

22. Doublier S, Ruotsalainen V, Salvidio G, Lupia E, Biancone L, Conaldi P, Reponen P, Tryggvason K, Camussi G 2001 Nephrin redistribution on podocytes is a potential mechanism for proteinuria in patients with primary acquired nephrotic syndrome. Am J Pathol 158:1723-1731

23. Inoue $\mathrm{T}$, Yaoita E, Kurihara H, Shimizu F, Sakai T, Kobayashi T, Ohshiro K, Kawachi H, Okada H, Suzuki H, Kihara I, Yamamoto T 2001 FAT is a component of glomerular slit diaphragms Kidney Int 59:1003-1012
24. Reiser J, Kriz W, Kretzler W, Mundel P 1999 The glomerular slit diaphragm is a modified adherens junction. J Am Soc Nephrol 11:1-8

25. Meyers KEC, Kujubu DA, Kaplan BS 1997 Minimal-change nephrotic syndrome. In: Neilson EG, Couser WG (eds) Immunologic Renal Diseases, vol. 1. LippincottRaven, Philadelphia, pp 975-992

26. Schnabel E, Anderson JM, Farquhar MG 1990 The tight junction protein ZO-1 is concentrated along slit diaphragms of the glomerular epithelium. J Cell Biol 111:1255-1263

27. Shih NY, Li J, Karpitskii V, Nguyen A, Dustin ML, Kanagava O, H MJ, Shaw A 1999 Congenital nephrotic syndrome in mice lacking CD2-associated protein. Science 286:312-315

28. Kaplan JM, Kim SH, North KN, Rennke H, Correia LA, Tung H-Q, Mathis BJ, Rodriquez-Perez J-C, Allen PG, Beggs AH, Pollak MR 2000 Mutations in ACTN4, encoding alpha-actinin-4, causes familial focal segmental glomerulosclerosis. Nat Genet 24:251-256

29. Putaala H, Soininen R, Kilpeläinen P, Wartiovaara J, Tryggvason K 2001 The murine nephrin gene is specifically expressed in kidney, brain and pancreas: inactivation leads to massive proteinuria and neonatal death. Hum Mol Genet $10: 1-8$ 